\title{
Knowledge, Attitude and Nutritional Status in Pregnant Women
}

\author{
Wiwit Widiastuti, ${ }^{1}$ Kuswandewi Mutyara, ${ }^{2}$ Amillia Siddiq ${ }^{3}$ \\ ${ }^{1}$ Faculty of Medicine Universitas Padjadjaran, ${ }^{2}$ Departmen of Public Health Faculty of Medicine \\ Universitas Padjadjaran, ${ }^{3}$ Department of Obstetrics and Gynecology Faculty of Medicine \\ Universitas Padjadjaran/Dr. Hasan Sadikin General Hospital Bandung
}

\begin{abstract}
Background: Nutrition during pregnancy is essential for a healthy pregnancy and childbirth. Malnutrition during pregnancy may cause a negative impact for both mother and fetus. Pregnant women have to replenish their nutritional intake so they have to know nutritional needs for pregnancy. This study aims to evaluate the association between knowledge towards the attitude and nutritional status among pregnant women in Jatinangor Primary Health Care.

Methods: This was a cross-sectional study and the subjects were 75 pregnant women selected by consecutive sampling while they attending Puskesmas Jatinangor for antenatal follow up in October until November 2012. Knowledge and attitude was assessed using a questionnaire. The level of knowledge and attitudes were categorized into insufficient, sufficient and good. Nutritional status was assessed by measuring the mid upper arm circumference. The level of nutritional status was categorized into good nutritional status and lower nutritional status.

Result: Out of 75 respondents, 24 respondents had good knowledge, 39 respondents had sufficient knowledge and 12 respondents had insufficient knowledge. 15 respondents had good attitude, 51 respondents had sufficient attitude, 9 had insufficient attitude. 62 respondents had good nutritional status and 13 respondents had lower nutritional status

Conclusion: Most of subjects have sufficient knowledge and attitude, and majority of the respondents have good nutritional status. There was significant relationship between knowledge and attitude $(p=0.02)$ and no significant relationship between knowledge and nutrition status $(p=0.666)$. Based on this study, it is expected to conduct further study about other factors which affect the knowledge, attitude, and practice of pregnant women to improve the nutritional status. [AMJ.2015;2(1):231-4]
\end{abstract}

Keywords: Attitude, knowledge, nutrition status, pregnancy

\section{Introduction}

Adequate nutritional intake during pregnancy is important to achieve healthy pregnancy. ${ }^{1}$ During pregnancy the nutritional needs of pregnant women will increase. Nutrition deficiency during pregnancy is harmful for both the mother and fetus. Insufficient of nutrition during pregnancy may cause insufficient nutrition to reach the fetus, intrauterine growth retardation, growth retardation, preterm labors, some inherited malformations, and pregnancy complication. ${ }^{2}$ Maternal nutritional problem that often occurs is anemic and chronic energy deficiency that could lead to high-risk pregnancies. Common causes of maternal deaths are haemorrhage and pre-eclampsia. ${ }^{3}$ There are many anatomical and physiological changes in the pregnant women, so the need for energy also increased approximately $14 \%{ }^{4}$ Pregnant women should pay more attention to nutritional intake, because they have to meet their own nutritional and also for the fetus.

Maternal dietary intake during pregnancy can be affected by several factors, including economic and social status, culture and educational level of the mother and her family. Malnutrition can result from ignorance of the pregnant mothers to their nutritional needs. The level of knowledge about the nutritional needs during pregnancy will affect the attitude and behavior of the mother in selecting food and regulate her diet. Therefore, research on the association between knowledge towards attitudes and nutritional status of pregnant women is needed.

Correspondence: Wiwit Widiastuti, Faculty of Medicine, Universitas Padjadjaran, Jalan Raya Bandung-Sumedang Km.21, Jatinangor, Sumedang, Indonesia, Phone: +6285647428742 Email: wwidiastuti7@gmail.com 
Table 1 Association between Nutrition Knowledge and Attitude Groups

\begin{tabular}{|c|c|c|c|c|c|c|c|}
\hline \multirow{3}{*}{ Knowledge Level } & \multicolumn{6}{|c|}{ Attitude } & \multirow{3}{*}{$\mathbf{P}$} \\
\hline & \multicolumn{2}{|c|}{ Good } & \multicolumn{2}{|c|}{ Sufficient $^{\mathrm{a}}$} & \multicolumn{2}{|c|}{ Insufficient $^{b}$} & \\
\hline & $\mathrm{n}$ & $\%$ & $\mathrm{n}$ & $\%$ & $\mathrm{n}$ & $\%$ & \\
\hline Good & 9 & 12 & 13 & 17.3 & 2 & 2.6 & \\
\hline Sufficient ${ }^{a}$ & 3 & 4 & 32 & 42.6 & 4 & 5.3 & 0.022 \\
\hline Insufficient $t^{b}$ & 3 & 4 & 6 & 8 & 3 & 4 & \\
\hline
\end{tabular}

\section{Methods}

This research was an analytical research using cross-sectional method. The study was conducted at the Jatinangor health center on October to November 2012 among pregnant women attended for antenatal care who are willing to be a subject of study, according to the consecutive sampling. Total subjects were 75 pregnant women.

Prior to the study, the respondents received explanation about the purpose of the study and the respondents were asked to sign a consent form. The data were taken using a questionnaire that has been validated. Demographic information was included at the first part of questionnaire.

Knowledge questionnaire consisted of 13 questions with choices of right or wrong answers. The second part was the attitude questionnaire consisted of 11 questions with the choices strongly disagree, disagree, agree, and strongly agree. Scores of knowledge and attitude were obtained by summation of each group question.

The level of knowledge and attitude will be divided into three groups: good, sufficient, and insufficient. Nutritional status was obtained by measuring the circumference of the upper arm using a tape measure and the results were grouped into two categories, good nutritional status if the size of the upper arm circumference greater than or equal to 23.5 $\mathrm{cm}$ and malnutrition status if the size of the upper arm circumference of less than 23.5 $\mathrm{cm}$. Association between knowledge towards attitudes and nutritional status analyzed by fisher's test.

\section{Result}

The majority of respondents in this study were 20 to 35 years old. Women in this study were either in first, second, or third trimester with more than half are in the third trimester. Most respondents graduated from high school and did not work. The average value of the respondents knowledge was $10.37 \pm 1.761$ with a range of values $0-13$ and the average value of the respondents attitude was $32.17 \pm 3.387$. Distribution of respondents based on nutritional status indicated that the majority of respondents had a good nutritional status, as many as 62 respondents $(82.7 \%)$

Result of this study showed a significant association between nutrition knowledge and attitude $(\mathrm{p}=0.022)$ and no significant association between nutrition knowledge and nutritional status $(\mathrm{p}=0.666)$.

\section{Discussions}

Knowledge is the result of the senses (eyes, nose, ears, skin, etc.) and are influenced by the intensity of the attention and the perception of

Table 2 Association between Nutrition Knowledge and Nutritional Status

\begin{tabular}{|c|c|c|c|c|c|}
\hline \multirow{3}{*}{ Knowledge Level } & \multicolumn{4}{|c|}{ Nutritional Status } & \multirow{3}{*}{$\mathbf{P}$} \\
\hline & \multicolumn{2}{|c|}{ Good } & \multicolumn{2}{|c|}{ Insufficient $^{b}$} & \\
\hline & $\mathrm{n}$ & $\%$ & $\mathrm{n}$ & $\%$ & \\
\hline Good & 21 & 28 & 3 & 4 & \\
\hline Sufficient ${ }^{a}$ & 33 & 44 & 6 & 8 & 0.666 \\
\hline Insufficient $^{b}$ & 8 & 10.6 & 4 & 5.3 & \\
\hline
\end{tabular}


an object. ${ }^{5}$ Knowledge influences the people's behavior. ${ }^{5}$ Knowledge is influenced by several factors such as level of education, employment, and age. ${ }^{6}$ Attitude is a close response to a stimulus or a particular object involving opinions and emotions, for example, agreedisagree, good-bad, and so on.7 Research conducted by Jonathan8 in 2010 showed that there were several predictors that can affect a person's attitude, such as ethnicity, education level, and level of knowledge. The act or practice is an embodiment of the attitude that supported by other factors such as facility or infrastructure. Research conducted in 2007 mentioned that the social demographics, such as education level, residence, and age also affect the behavior. ${ }^{9}$

In this study, a significant association has been found between the knowledge level of nutrition with the attitude of respondents $(p<0.05)$. This suggests that the level of knowledge of pregnant women in the study population is related to the readiness or willingness of respondents to act. Research conducted in 2011 about the relationship of knowledge, attitudes, and practices of nutrition also showed similar results, that there is a correlation between knowledge and attitude. ${ }^{7}$

In the fisher's test, there is no significant association between the level of knowledge and nutritional status of pregnant women $(p>0.05)$. This suggests that the level of knowledge does not affect the nutritional behavior of pregnant women thus had no effect on nutritional status. Similar results were also found in a study conducted in 2007 that the level of nutrition knowledge is not related to behaviour. ${ }^{10}$ Study conducted in 2012 also showed similar results, it is due to the fact that some people may have strict rules with the diet so it is difficult to change, and due to economic conditions, irregular diet or because of the different flavors of food. ${ }^{11}$ Similarly, in a study conducted in 2004 states that there were many factors can influence the behavior of a person, such as age, education, race, socioeconomic, cultural, and social support. ${ }^{12}$ Someone with higher incomes and higher education levels have better behavior than those with lesser education and income. That study explains that attitudes, subjective norms, and views a person has a strong link with the behavior. ${ }^{12}$

In general, the level of knowledge will affect a person's behavior. However, the level of knowledge is not related to the nutritional status. This could be due to many other factors that influence a person's behavior, as already mentioned above, namely age, education level, occupation and income. In addition to external factors such as facilities and sociocultural factors and internal factors such as confidence and motivation also affect behavior. ${ }^{5}$

Based on the results, it can be concluded that most of the respondents have a sufficient level of knowledge of as many as 39 people (52\%), more than half of the respondents have a sufficient attitude as many as 51 people (68\%), and as many as 62 people ( $82.7 \%$ ) had a good nutritional status. There is a significant relationship between the level of knowledge of nutrition with nutritional attitudes and there is no significant relationship between the level of knowledge of the nutritional status.

The Jatinangor Public Health Center can organize counseling for pregnant women to increase their knowledge about the nutritional needs of pregnant women, to see how many respondents have sufficient levels of nutrition knowledge. In addition, the need to identify other factors that cause nutritional problems, which consist of the external and internal factors, should be determined in order to find a solution.

\section{References}

1. Abu-Saad K, Fraser D. Maternal nutrition and birth outcomes. Epidemiol Rev. 2010;32(1):5-25.

2. Hyatt MA, Gardner DS, Sebert $S$, Wilson V, Davidson N, Nigmatullina $Y$, et al. Suboptimal maternal nutrition, during early fetal liver development, promotes lipid accumulation in the liver of obese offspring. Reproduction. 2011;141(1):119-126.

3. Ones. Target penurunan angka kematian ibu (AKI) sulit tercapai. Bandung: Dinas Provinsi Jawa Barat; 2012. [Cited 2012 Mei 5]. Available from: http://jabarprov.go.id/ index.php/subMenu/informasi/berita/ detailberita/4097.

4. Hanretty KP. Obstetrics illustrated. London: Churchill Livingstone; 2003

5. Notoatmodjo PDS. Ilmu perilaku kesehatan. Jakarta: Rineka Cipta; 2010.

6. GaneshK. Knowledgeand attitude ofmental illness among general public of Southern India. National journal of community medicine. 2009; 2(5): 176-8. [Cited 12 December 2012]. Available from: http:// njcmindia.org/uploads/2-1_175-178.pdf

7. Azizi M, Aghaee N, Ibrahimi M, Ranjbar 
K. Nutrition knowledge, the attitude, and practices of college students. Facta Universitatis: Series Physical Education and Sport. 2011;9(3):351-5. [Cited 2 December 2012]. Available from: http:// facta.junis.ni.ac.rs/pe/pe201103/ pe201103-12.pdf

8. Yap J, Lee VJ, Yau TY, Ng TP, Tor P-C. Knowledge, attitudes, and practices toward pandemic influenza among cases, close contacts, and health care workers in tropical Singapore: a cross sectional survey. BMC Public Health. 2010;10:442.

9. Kusumastuti I. Association between knowledge, attitudes and sexual practices among unmarried Indonesian young adults: A Study From Indonesian Young Adult Reproductive Health Survey [Thesis]. Bangkok: Mahidol University; 2007.

10. Shakkour E. The relationship between nutritional knowledge and application [Thesis]. Spring: Liberty University; 2007.

11. Verpuri J. Breastfeeding Knowledge, and Attitudes, Beliefs, and Intentions Regarding Breastfeeding in the Workplace Among Students and Professionals in Health-Related Fields [Dissertation]. Blacksburg: Virginia Polytechnic Institute and State University ; 2004. 